\title{
Epidemiological survey of Rheumatic fever, Rheumatic heart disease and Congenital heart disease among school children in Kathmandu valley of Nepal
}

\author{
Dipanker Prajapati*1, Deewakar Sharma ${ }^{1}$, Prakash Raj Regmi², Harihar Khanal², \\ Sajan Gopal Baidya ${ }^{1}$, Sujeeb Rajbhandari ${ }^{1}$, Madhu Rokka ${ }^{3}$, Sarju Raj Singh ${ }^{3}$, \\ Anmol Shrestha $^{3}$, Abha Shrestha ${ }^{3}$, Rupesh Jung Belbase ${ }^{3}$, Sambridhi Sulpya ${ }^{3}$ \\ ${ }^{1}$ Shahid Gangalal National Heart Centre, Bansbari, Kathmandu \\ ${ }^{2}$ National Academy of Medical Sciences, Bir Hospital, Kathmandu \\ ${ }^{3}$ Lalitpur Heart Clinic, Nepal Heart Foundation,Lalitpur Branch,Lalitpur
}

\section{Citation \\ Prajapati D, Sharma D, Regmi $P R$, et al Epidemiological survey of Rheumatic fever, Rheumatic heart disease and Congenital heart $R$ disease among school children in Kathmandu valley of Nepal. Nepalese Heart Journal 2013;10(1):1-5.}

Keywords

Congenital Heart Disease, Prevalence, Rheumatic Heart Disease, School Children

\begin{abstract}
Background and Aims: Rheumatic Fever, Rheumatic Heart Disease and Congenital Heart disease are the most common cardiac problems in school children. Prior studies have reported different prevalence rate of Rheumatic Heart Disease among different groups of population of Nepal. The aim of this study was to estimate the prevalence of Rheumatic Fever, Rheumatic Heart Disease and Congenital Heart Disease among school children in Kathmandu Valley of Nepal.
\end{abstract}

Methods: Cardiac screening of 34,876 school children from 115 randomly selected public schools from two cities of Kathmandu Valley (Kathmandu and Lalitpur) was done. Cases with abnormal findings in auscultation underwent echocardiography and the diagnosis was confirmed.

Results: The prevalence of Congenital Heart Disease was noted to be 1 per thousand and prevalence of Rheumatic Heart Disease was found to be 0.90 per thousand (in the age group 5-16 years) with the most common lesion being Mitral Regurgitation. No significant statistical difference was noted between male and female students in both the cases of Rheumatic Heart Disease and Congenital Heart Disease. No cases of Acute Rheumatic Fever were noted.

Conclusion: The prevalence of Rheumatic Heart Disease among school children in Kathmandu valley was noted to be lower than reported in similar previous studies. Primary and secondary prevention programs of RF/RHD have been effective in Nepal and are needed to be strengthened and expanded to further reduce the burden of these diseases.

\section{BACKGROUND}

Rheumatic Fever (RF), Rheumatic Heart Disease (RHD) and Congenital Heart Disease (CHD) are the most common cardiovascular diseases among school children and young adults. In 2005, 15.6 million people were estimated to have RF or RHD on the basis of traditional clinical measures that may represent substantial underestimation ${ }^{1}$. The majority of these cases were from sub-Saharan

\footnotetext{
*Corresponding author:

Dipanker Prajapati

Shahid Gangalal National Heart Centre,

Bansbari, Kathmandu, Nepal

Email: dpcardio@hotmail.com
} 
Africa and south central Asia, which along with indigenous populations in Australia and New Zealand represented the world's highest prevalence ${ }^{2}$. Congenital heart disease (CHD) is reported to affect almost 8/1000 live births ${ }^{3}$.

Rheumatic and congenital heart diseases are significant causes of morbidity and mortality among Nepalese school children ${ }^{4}$. The prevalence of CHD and RHD in school children has been scarcely studied in Nepal. Studies done in different parts of our country in the last two decades have shown prevalence of RHD to vary from 1.2 to 1.35 per thousand school aged children and prevalence of CHD to be 1.3 per thousand ${ }^{4-7}$.

The aim of this study was to report the findings of cardiac screening among school children of the Kathmandu valley. This study focused on school children of urban as well as rural population in Kathmandu Valley and aimed to see the trend of the disease compared to findings from prior studies which were done in the last two decades in Nepal.

\section{METHODS}

This study enrolled a total of 37,565 children from two cardiac screening programs. The first one which was jointly conducted by Nepal Heart Foundation and Rotary Club of Patan Durbar Square enrolled 32,315 students and the other which was conducted by Nepal Heart Foundation alone enrolled 5,250 students. Cardiac screening was done in premises of different schools. Detailed check up was done at Lalitpur heart clinic (a community clinic run by Nepal Heart Foundation).

Survey was done in randomly selected 115 government schools, some of which consisted of pre-school, in Kathmandu valley (Kathmandu and lalitpur districts) in the period from November 2011 to June 2013. The students mainly belonged to low and middle socio-economic classes. Our survey team consisted of 10 physicians, among which 4 were Cardiologists and the others were working in cardiology department with good exposure in cardiology. The whole survey was supervised by a senior cardiologist. All the students underwent history taking and physical examination. History of past and present joint pains, fever, sore throat, palpitation, fatigue, shortness of breath, and chest pain were elicited and recorded on an initially prepared screening Proforma. Clinical examination was performed to look for objective evidence of RF, RHD and CHD. Particular care was taken in cardiac auscultation of the child in erect, left lateral and recumbent positions.

The absentees during the first visit were followed and examined in subsequent visits. The children with murmurs of Grade II or more and features of CHD were listed among suspected cases. The suspected cases were subjected to echocardiography in Lalitpur Heart Clinic. Echocardiography test was performed in Medison EKO7 model echocardiography machine with 2-4 MHz transducer. World Health Organisation Echocardiography criteria for RHD 2005 were used for diagnosis of RHD and modified Jones criteria (1982) were used for the diagnosis of Acute Rheumatic Fever.

Schools were visited repeatedly to cover maximum number of enrolled students. The list of absent students was maintained. About $12 \%$ of students were found to be absent on the first visit. Inquiry was made with the fellow students, concerned class teachers to know whether they were absent due to illness. Such absent students were examined on subsequent visits. Despite all our efforts, 7.1\% (2689 students) could not be examined but it was made sure that the absence was not due to illness.

\section{STATISTICAL ANALYSIS}

Statistical Analysis was done using SPSS version 16.0. Number and age were described as mean and standard deviation (SD). Male and female were compared using descriptive crosstab analysis. $\mathrm{p}$ value $<0.05$ is considered as significant.

\section{RESULTS}

Out of the enrolled 37,565 students, 34,876 (92.8\%) were examined. There were 19198 (55.04\%) males and $15,678(44.96 \%)$ females.

\section{Table 1: Age and Sex distribution}

\begin{tabular}{cccc}
\hline Age Group & Male $(\mathbf{\%})$ & Female $(\%)$ & Total $(\%)$ \\
\hline$<5$ years & $306(0.88 \%)$ & $206(0.59 \%)$ & $512(1.47 \%)$ \\
$5-16$ years & $16448(47.16 \%)$ & $13457(38.58 \%)$ & $29905(85.75 \%)$ \\
$>16$ yrs & $2444(7.0 \%)$ & $2015(5.78 \%)$ & $4459(12.78 \%)$ \\
Total & $19198(55.04 \%)$ & $15678(44.96 \%)$ & $34876(100 \%)$ \\
\hline
\end{tabular}


Age of the study sample ranged from 1.5 year to 21 years with the mean age being $10.74 \pm 4.23$ years.

The mean age of males was $10.64 \pm 4.24$ years and of females was $10.87 \pm 4.20$ years. The mean age of males in age group of $<5$ years, 5-16 years and $>16$ years were $2.85 \pm 0.98$ years, $9.66 \pm 3.32$ years and $17.18 \pm 2.1$ years respectively, whereas the mean age of female in the same age groups were $2.77 \pm 0.99$ years, $9.90 \pm 3.30$ years and $17.14 \pm 2.018$ years respectively.

There were 753 suspected cases that underwent echocardiography test. Among these cases, 30 $(0.086 \%)$ had Rheumatic Heart Disease and 38 $(0.10 \%)$ had Congenital Heart Disease.

\section{Table 2: Prevalence of RHD}

\begin{tabular}{|cccc}
\hline $\begin{array}{c}\text { Age } \\
\text { Group }\end{array}$ & $\begin{array}{c}\text { Total } \\
\text { Population }\end{array}$ & $\begin{array}{c}\text { RHD } \\
\text { Population }\end{array}$ & Prevalence \\
\hline < years & 512 & 0 & 0 \\
5-16 years & 29905 & 27 & $0.090 \%$ \\
$>16$ yrs & 4459 & 3 & $0.06 \%$ \\
Total & 34876 & 30 & $0.086 \%$ \\
\hline
\end{tabular}

No RHD case was found in age group below 5 years. 27 cases $(0.09 \%)$ of RHD was detected in age group 5-16 years. The prevalence of RHD was found to be 0.90 per 1000 in this age group. There were 13 males $(0.043 \%)$ and 14 females $(0.047 \%)$ with RHD in this age group $(\mathrm{p}$ value $=0.474)$ and 1 male $(0.02 \%)$ and 2 females $(0.04 \%)$ in the age group of $>16$ years $(p$ value $=0.455)$. No significant statistical difference was noted between both sex. No case of Acute Rheumatic Fever was detected during screening and study period.

Among the cases of Rheumatic Heart Disease, Mitral Regurgitation (MR) was the most common followed by Mitral Stenosis (MS) and Aortic Regurgitation (AR) respectively. Combined valvular involvement was found in even fewer numbers.

\section{Table 3: Types of Valvular Lesions}

\begin{tabular}{lcccc|}
\multicolumn{1}{c}{$\begin{array}{c}\text { Valvular } \\
\text { Involvement }\end{array}$} & Male & Female & Total & p value \\
\hline $\begin{array}{l}\text { Mitral Stenosis (MS) } \\
\begin{array}{l}\text { Mitral Regurgitation } \\
\text { (MR) }\end{array}\end{array}$ & 4 & 4 & 8 & 0.774 \\
Aortic Stenosis (AS) & - & - & - & - \\
$\begin{array}{l}\text { Aortic Regurgiation } \\
\text { (AR) }\end{array}$ & 1 & 2 & 3 & 0.450 \\
MS+MR & - & - & - & - \\
MS+MR+AS+AR & - & 2 & 2 & 0.118 \\
Total & 14 & 16 & 30 & 0.356 \\
\hline
\end{tabular}

There was no significant difference in prevalence of RHD in both sexes ( $p$ value $>0.05$ ).
Table 4: Prevalence of Congenital Heart Disease

\begin{tabular}{lcccc}
\hline Age & Male (\%) & Female (\%) & Total & p value \\
\hline \multirow{2}{*}{ 5 yyears } & 3 & 2 & 5 & 0.991 \\
& $(0.58 \%)$ & $(0.39 \%)$ & $(0.98 \%)$ & \\
$>5$ years & 13 & 20 & 33 & 0.072 \\
Total & $(0.037 \%)$ & $(0.058 \%)$ & $(0.096 \%)$ & \\
& $(.046 \%)$ & $(0.063 \%)$ & $(0.10 \%)$ & 0.109 \\
\hline
\end{tabular}

Among students with congenital heart disease, Atrial Septal Defect (ASD) was the most common followed by Ventricular Septal Defect (VSD). Two cases of Persistent Ductus Arteriosus (PDA) were found.

\section{Table 5: Types of Congenital Heart Disease}

\begin{tabular}{lcccc}
\multicolumn{1}{c}{ Types of CHD } & Male & Female & Total & p value \\
\hline $\begin{array}{l}\text { Atrial Septal Defect } \\
\begin{array}{l}\text { ASD) } \\
\text { Aentricular Septal Defect }\end{array}\end{array}$ & 7 & 11 & 18 & 0.168 \\
$\begin{array}{l}\text { VSD) } \\
\text { Persistent Ductus }\end{array}$ & - & 3 & 3 & 0.055 \\
$\begin{array}{l}\text { Arteriosus (PDA) } \\
\text { Valvular Aortic Stenosis }\end{array}$ & 1 & - & 1 & 0.366 \\
$\begin{array}{l}\text { AS) } \\
\text { Valvular Pulmonary }\end{array}$ & - & 1 & 1 & 0.268 \\
$\begin{array}{l}\text { Stenosis (PS) } \\
\text { Myxomatous mitral valve } \\
\text { causing severe MR }\end{array}$ & - & 1 & 1 & 0.268 \\
$\begin{array}{l}\text { Endocardial cushion } \\
\text { defect }\end{array}$ & 1 & 1 & 2 & 0.886 \\
$\begin{array}{l}\text { Congenitally Corrected } \\
\text { Transposition of Great }\end{array}$ & 1 & 0 & 1 & 0.366 \\
$\begin{array}{l}\text { Arteries (CCTGA) } \\
\text { Total }\end{array}$ & 16 & 22 & 38 & 0.109 \\
\hline
\end{tabular}

There was no significant difference in prevalence of CHD in both sex.

\section{DISCUSSION}

RHD is the second commonest cause of hospital admission in cardiology department as well as the second commonest cause for open heart surgery in $\mathrm{Nepal}^{8,9}$. The prevalence of RHD in developed countries declined sharply in last decades, which was observed especially after the introduction of antibiotics and preventive programs. However RHD consolidates a spectrum of different stages of clinically silent and clinically manifest valvular degeneration culminating in congestive heart failure, increasing the risk of endocarditis, cerebro vascular events and eventually leading to premature death of the affected working-age population in developing countries ${ }^{10}$. The WHO has recommended echocardiographic screening of RHD in highprevalence regions ${ }^{11}$. Early detection of subclinical RHD by use of Echocardiography warrants timely implementation of secondary antibiotic prophylaxis and may prevent progression of valvular damage leading to congestive heart failure. Prior studies ${ }^{12,13}$ have shown the prevalence of RHD among school children to be 1.35 per thousand in rural community 
of the hill region ${ }^{5}$ and 1.2 per thousand in Kathmandu city $^{6}$. Similar findings were reported in other Asian countries $^{14-20}$

The result of our study shows that RHD and CHD were still prevalent among school children in Kathmandu Valley. Male population exceeded in number compared to females in our study. The primary reason might be due to easy access for education among males compared to females in our society, mainly due to financial and cultural restrictions to females.

Compared to similar previous studies, the incidence of RHD among school children was found to be less. One of the reasons for this might be the preventive programs, both primary and secondary, that have been implemented since previous studies. The other reason might be the increased awareness and medical facilities in the study area, with the improvement in living standard of the population.

The estimates presented in our study are only for clinically significant RHD, that is, for cases who present minimum with murmur of grade 2 or more. Only $2.15 \%$ of total screened population underwent echocardiography test. Therefore, higher prevalence of clinically silent RHD and RF in the phase of remission could not be ruled out.

In our study, RHD and CHD were more common in females $(53.33 \%$ and $57.90 \%$, respectively) than in males ( $46.67 \%$ and $42.10 \%$, respectively), however, no statistical significant difference were noted. Mitral valve was the most often involved valve with Mitral Regurgitaion being the most common valve lesion, followed by MS and AR.
In our study, $\mathrm{CHD}$ was found in $0.10 \%$ of total screened school children, which is similar to previous studies $^{4}$. The reported frequency of congenital heart disease in children is influenced by the standards of health care and availability of cardiac services to detect and treat such children. In Nepal, many infants are delivered at home and a large proportion of the population is served by primitive rural health clinics. However true prevalence of CHD might be higher as the infants and the children who couldn't attend school were not screened in our study. Other reason might be due to lack of preventive measures for $\mathrm{CHD}$ and lack of wide spread fetal screening programs, the fetal echo service being available to limited population only.

ASD was more common, followed by VSD and PDA. Female preponderance was noted in ASD population; however, no statistical significant difference was noted.

\section{CONCLUSION}

RHD and CHD are still prevalent among school children in Kathmandu Valley. The decrease in the prevalence of RHD shows that Primary and secondary prevention programs for RF/RHD in Nepal conducted by the Government of Nepal and Nepal heart foundation have been found to be effective in reducing the burden of this disease. These programs need to be further strengthened and expanded to reduce the morbidity and mortality from RF/RHD. For prevention of CHD, special programs focusing in raising awareness on risk factors of CHD among pregnant women, developing fetal screening programs, etc are needed.

\section{REFERENCES}

1. Marijon E, Ou P, Celermajer DS, et al: Prevalence of rheumatic heart disease detected by echocardiography screening. N Engl L Med 2007;357:470.

2. B. Soma Raju, Zoltan G. Turi. Rheumatic Fever. In: Bonow, Mann, Zipes, Libby. Braunwald's Heart Disease, Elsevier Saunders, $9^{\text {th }}$ edition, 2012:1868.

3. Michael D Freed, William H Plauth. The pathology, pathophysiology, recognition and treatment of congenital heart diseases. In: Braunwald-Heart Disease-A Textbook of Cardiovascular Medicine, 6th Ed, Eds Braunwald E, Zipes DP, Libby Peter, Philadelphia, WB Saunders Company, 2001.1925-1993.

4. KC MB, Sharma D, Shresth MP et al, Prevalence of rheumatic and congenital heart disease in school children of Kathmandu valley in Nepal,
Indian Heart Journal, 2003;55(6):615-8.

5. Shrestha UK, Bhattarai TN, Pandey MR. Prevalence of rheumatic fever and rheumatic heart disease in school children in rural community of the hill region of Nepal. Indian Heart J 1991:43:39-41.

6. Regmi PR, Pandey MR. Prevalence of rheumatic fever and rheumatic heart disease in school children of Kathmandu city. Indian Hear J 1997;49:518-520.

7. Limbu Y R, Maskey A. Current status of Rheumatic Fever and Rheumatic Heart Disease in Nepal. Journal of Nepal Medical Association 2002; 41: 514-517.

8. Shahid Gangalal National Heart Centre, Annual Report: Medical Ward. Year 2012, 30-32.

9. Shrestha BMS, Koirala B, Joshi PR et al. Beginning open heart surgery in Nepal: our experience and three years audit at Tribhuwan University Teaching Hospital. Nepalese Heart 


\section{J 2000:36-43.}

10. Shrestha NR, Kalesan B, Karki $P$, et al. Rheumatic heart disease: pilot study for a population based evaluation of prevalence and cardiovascular outcomes among schoolchildren in Nepal. BMJ Open 2012;2: e001616. doi:10.1136/ bmjopen-2012-001616.

11. Carapetis J, Parr J, Cherian T. Standartization of epidemiologic protocols for surveillance of post-streptococcal sequelae: acute rheumatic fever, rheumatic heart disease and acute poststreptococcal glomerulonephritis. Department of Health and Human Services, National Institutes of Health (online). 2010. http://www. niaid.nih.gov/ topics/strepThroat/Documents/ groupasequelae.pdf

12. Carapetis J.R. Rheumatic Heart Disease in Asia. Circulation,2008;118:2748-2753.

13. Regmi PR, Wyber R. Prevention of Rheumatic Fever and Heart Disease: Nepalese Experience. Global Heart,2013;8-3:247-252.

14. Jose VJ, Gomathi M. Declining prevalence of rheumatic heart disease in rural schoolchildren in India: 2001-2002. Indian Heart J. 2003;55: 158-160.

15. Periwal KL, Gupta BK, Panwar RB, Khatri PC, Raja S, Gupta R. Prevalence of rheumatic heart disease in school children in Bikaner: an echocardiographic study. J Assoc Physicians
India. 2006;54:279-282.

16. Chen X, Zhang M, Huang D, Huang M, Xiong Y, Xie M, Shou Y, Li M, Wu C, Zeng H, Li $\mathrm{X}$, Zheng $\mathrm{M}$. An epidemiologic investigation of acute rheumatic fever and rheumatic heart disease among students aged 5-18 in west area of Sichuan Province [in Chinese]. Sichuan Da Xue Xue Bao Yi Xue Ban. 2003;34:533-535.

17. Marijon E, Ou P, Celermajer DS, Ferreira B, Mocumbi AO, Jani D, Paquet C, Jacob S, Sidi D, Jouven X. Prevalence of rheumatic heart disease detected by echocardiographic screening. N Engl J Med. 2007; 357:470-476.

18. Grover A, Dhawan A, Iyengar SD, Anand IS, Wahi PL, Ganguly NK. Epidemiology of rheumatic fever and rheumatic heart disease in a rural community in northern India. Bull World Health Organ. 1993;71:59-66.

19. Kumar P, Garhwal S, Chaudhary V. Rheumatic heart disease: a school survey in a rural area of Rajasthan. Indian Heart J. 1992;44:245-246. 12. Vashistha VM, Kalra A, Kalra K, Jain VK. Prevalence of rheumatic heart disease in school children. Indian Pediatr. 1993;30:53-56.

20. Patel DC, Patel NI, Patel JD, Patel SD. Rheumatic fever and rheumatic heart disease in school children of Anand. J Assoc Physicians India. 1986;34:837-839. 